Risks of Mortality and Morbidity from Worldwide Terrorism:

1968-2004

K. T. Bogen, E. D. Jones

March 17, 2005

Risk Analysis 
This document was prepared as an account of work sponsored by an agency of the United States Government. Neither the United States Government nor the University of California nor any of their employees, makes any warranty, express or implied, or assumes any legal liability or responsibility for the accuracy, completeness, or usefulness of any information, apparatus, product, or process disclosed, or represents that its use would not infringe privately owned rights. Reference herein to any specific commercial product, process, or service by trade name, trademark, manufacturer, or otherwise, does not necessarily constitute or imply its endorsement, recommendation, or favoring by the United States Government or the University of California. The views and opinions of authors expressed herein do not necessarily state or reflect those of the United States Government or the University of California, and shall not be used for advertising or product endorsement purposes. 
UCRL-JRNL-210608

\title{
Risks of Mortality and Morbidity from Worldwide Terrorism: 1968-2004
}

\author{
Kenneth T. Bogen ${ }^{1}$ and Edwin D. Jones ${ }^{2}$ \\ To appear in vol. 26 (2006) of the journal: \\ Risk Analysis \\ ${ }^{1}$ Environmental Science Division, and \\ ${ }^{2}$ Risk and Response Management Program \\ Lawrence Livermore National Laboratory \\ University of California, Livermore, CA 94550, USA
}

February 10, 2005

Revised: July 11, 2005

Accepted: Aug. 26, 2005 (in press)

*To whom correspondence should be addressed at: Environmental Science Div. (L-396), Lawrence Livermore National Laboratory, 7000 East Avenue, Livermore, CA 94550-9900, USA, TEL: (925) 422-0902, FAX: (925) 424-3255, NET: bogen@LLNL.gov.

Abbreviations: $\mathrm{AE}=$ adverse event, $\mathrm{ANOCOVAR}=$ analysis of covariance, $\mathrm{CL}=$ confidence limits, GEV = generalized extreme value, GP = generalized Pareto, HOT = highly optimized tolerance, MIPT $=$ Memorial Institute for the Prevention of Terrorism. 


\begin{abstract}
Worldwide data on terrorist incidents between 1968 and 2004 gathered by the RAND corporation and the Oklahoma City National Memorial Institute for the Prevention of Terrorism (MIPT) were assessed for patterns and trends in morbidity/mortality. Adjusted data analyzed involve a total of 19,828 events, 7,401 "adverse" events (each causing $\geq 1$ victim), and 86,568 “casualties" (injuries) of which 25,408 were fatal. Most terror-related adverse events, casualties and deaths involved bombs and guns. Weapon-specific patterns and terror-related risk levels in Israel (IS) have differed markedly from those of all other regions combined (OR). IS had a fatal fraction of casualties about half that of OR, but has experienced relatively constant lifetime terror-related casualty risks on the order of $0.5 \%$ - a level 2 to 3 orders of magnitude more than those experienced in OR that increased $~ 100$-fold over the same period. Individual event fatality has increased steadily, the median increasing from 14 to $50 \%$. Lorenz curves obtained indicate substantial dispersion among victim/event rates: about half of all victims were caused by the top $2.5 \%$ (or 10\%) of harm-ranked events in OR (or IS). Extreme values of victim/event rates were approximated fairly well by generalized Pareto models (typically used to fit to data on forest fires, sea levels, earthquakes, etc.). These results were in turn used to forecast maximum ORand IS-specific victims/event rates through 2080, illustrating empirically based methods that could be applied to improve strategies to assess, prevent and manage terror-related risks and consequences.
\end{abstract}

Key words: Extreme value, homeland security, modeling, generalized Pareto 


\section{Introduction}

Over the last four decades, but particularly since events on September 11, 2001, data and interest have grown pertaining to trends and patterns in global terrorism and strategies to combat it (e.g., Fowler, 1981; Congleton, 2002; Cordes et al., 1984; Hoffman, 1997,1998; Smithson, 2000a; Frey and Leuchinger, 2003). Since 2001, the RAND corporation and the Oklahoma City National Memorial Institute for the Prevention of Terrorism (MIPT) have worked to prepare an online database of terrorism incidents to help researchers, analysts, and others working to prevent terrorism (Ellis, 2004). The resulting MIPT Terrorism Database System now provides public access to comprehensive information and intelligence on terrorism, including two RAND databases containing date, location and victim-rate data for specific events: the RAND Terrorism Chronology Database, and the RAND-MIPT Terrorism Incident Database (MIPT, 2004a). The Chronology Database records international terrorist incidents that occurred between 1968 and 1997, while the Incident Database records domestic as well as international terrorist incidents that occurred from 1998 to the present (MIPT, 2004b). Input to these databases is stated as being obtained from open source materials (e.g., newspapers) after review to verify accuracy (MIPT, 2004c).

The two RAND-MIPT data sets pertaining to terrorist incidents from 1968 to the present (referred to hereafter jointly as RAND-MIPT data) reflect a definition of terrorism not by perpetrator identity, but rather by whether acts reflect "violence calculated to create an atmosphere of fear and alarm" to coerce others into action or inaction not otherwise undertaken, generally directed against civilian targets, with motives that are political expressed through actions generally carried out in a way that achieves maximum publicity (MIPT, 2004b). This definition of terrorism is similar to that used by others studying terrorism, e.g. Frey and 
Leuchinger (2003) define terrorists as "perpetrators [who] (i) use force on civilians; (ii) act in an unofficial capacity ... in particular, not [as] part of the national army and ... not wear[ing] any national uniform; (iii) want to achieve political goals; (iv) aim to have far-reaching effects beyond the immediate victims, particularly through the media."

RAND-MIPT data contain publicly accessible data that may be used, certainly as a starting point, to characterize historical patterns and possible trends concerning, among other things, mortality and morbidity risks imposed by terrorism. However, these data are provided with the caveat that they are "intended only to aid those seeking to better comprehend terrorism and should not be used as a tool for any sort of analysis, predictive or otherwise" (MIPT, 2004c). This caveat suggests that patterns or trends that may be evident in the data may be spurious, or artifacts of data collection methods used, etc. The present study was undertaken to assess this possibility, by examining the data for patterns and trends in a way that accounts for statistical error as well as the major discontinuity starting in 1998 in the definition used for included events.

Primary endpoints examined were rates of mortality and morbidity due to terrorist events over time and per event, and how these rates may vary by geographic region, target, and weapon used. Extreme-value distributions of victims/event were also examined. If extreme values of a phenomenon arise from independent stochastic variation acting on a homogeneous underlying mechanism, their statistical distribution should be a member of a generalized extreme value family of distributions readily characterized by statistical methods (Coles and Pericchi, 2003). This type of analysis is often done on data pertaining to temperature, wind speed, rainfall, sea and river levels, wave heights, material breaking strength, earthquakes, etc. Irregularities or discontinuities in extreme-value distributions for data on victims/event exhibited in meaningful 
subsets of the data analyzed would indicate underlying non-homogeneities due not likely to chance, but rather to mixed underlying mechanisms, sampling bias, effects of unidentified covariates, data inconsistencies, or other factors. Methods described below were used along these lines to assess RAND-MIPT data, after first adjusting (as described below) a single but quite large, erroneous casualty estimate that appears in those data for the 1995 Tokyo subway attack involving sarin gas. Apparent trends and patterns revealed by this analysis are summarized in Results, followed by a discussion of potential key limitations and implications.

Analyses reported here were done using RAND-MIPT web-accessible data described (at the time this report was prepared) as being last updated on November 24, 2004 (MIPT, 2004a, 2004c). Historical data made available from this source are subject to modification and are updated regularly with new information, which may affect results of any future study done along the lines of that reported here.

\section{Methods}

As of mid-December, 2004, RAND-MIPT data were divided into two different datasets: incidents collected between 1968 and 1997 (the "RAND Terrorism Chronology") only account for international terrorism (incidents in which the perpetrators cross national boundaries strike targets, select domestic targets with a foreign state association or create an international incident by attacking airline passengers or equipment, where as data from 1998 to the present include domestic terrorism incidents (perpetrated by local nationals against a purely domestic target) as well as international incidents (MIPT, 2004b).

About $5.5 \%$ of all casualties (i.e., injuries + deaths) included in RAND-MIPT data reflect 5,000 injuries plus 12 deaths attributed by the database to the Aum Shinrikyo attack involving 
release of sarin gas in the Tokyo subway system on March 20, 1995. The source of this estimate is listed as being "Chronology Data" logged on April 3, 1995, just two weeks after the event. However, it was later established that the vast majority (well over 70\%) of the $>5,500$ patients seen in Tokyo clinics for symptoms associated with coordinated releases of a total of $\sim 4.7$ liters of sarin on five subway cars suffered no real physical symptoms at all, and that the nearly all remaining patients seen suffered only mild myosis and/or headache lasting <24 h, except for 17 critically injured patients (12 of whom later died), 37 severely injured patients, and a number of moderately injured patients who were non-ambulatory with non-mild physical symptoms, 107 of the latter having been treated at St. Luke's Hospital that "bore the brunt of the disaster" (Smithson, 2000b). Additional stress-related psychological symptoms were reported after the event (Smithson, 2000b). For the purpose of the present study, total injuries associated with this incident were taken to comprise all (54) of those severely and critically injured, plus all of those injured moderately as defined above, the latter number here estimated to be 180 . So corrected to adjust for injuries associated with the 1995 Tokyo subway incident, the data analyzed shall be referred to as RAND-MIPT-TC data.

RAND-MIPT-TC data were divided into 5-y periods starting in 1968-1972; event, death and casualty data for 2005-2007 during the final period were estimated by multiplying corresponding data obtained for 2003-2004 by the ratio (5 years)/(2 years). Database variables addressed were: time period, casualties (injuries + deaths), deaths, "adverse" events (AEs, meaning terrorist events that caused one or more casualties), world region (Africa, East Central Asia, Eastern Europe, Israel, Latin America, Near East [excluding Israel and the Occupied Territories], North America, the Occupied Territories, South Asia, Southeast Asia and Oceana, and Western Europe), weapon type (Biological, Bomb, Chemical, Fire, Guns, Remote-controlled Bomb, 
Bladed Weapons such as knives, and Other), and target (Airport \& Airlines, Business, Diplomatic, Government, Military, Police, Private Citizens/Property, Religious Figures \& Institutions, Transportation, and Other), where "Other" denotes unknown, unavailable, unidentified, or otherwise not included in the database. Corresponding world-region population data were obtained from an international population database (USBC, 2004).

The following terms and notation are used: "event" $=$ terrorism "incident", $F_{\text {adv }}=$ fraction of events that caused casualties, $F_{\text {fat }}=$ "fatal fraction" of adverse-event-induced casualties (i.e., fraction of casualties representing deaths $)$, and $\mathrm{X}_{0}(=-a / b)=$ the abscissa intercept of a linear fit $\mathrm{Y}=a+b \mathrm{X}$ conditional $\mathrm{Y}=0$. The fraction $F_{\text {fat }}$ is referred to as an "unweighted" average when calculated as $F_{\text {fat }}=k^{-1} \square m_{i} / c_{i}$, and as a "casualty-weighted" average when calculated instead as $F_{\text {fat }}=\square m_{i} / \square c_{i}=\square w_{i}\left(m_{i} / c_{i}\right) / \square w_{i}$ with weights $w_{i}=c_{i}$, where $m_{i}=$ deaths and $c_{i}=$ casualties

per $i$ th adverse event $\mathrm{AE}_{i}$, and summation $(\square)$ is over all $k$ corresponding $\mathrm{AE}_{i}, i=1, \ldots, k$ within a specific period or region. The weighted mean fraction $F_{\text {fat }}$ is thus synonymous with the ratio of total deaths to total casualties within one or more specified categories.

Significance of differences in means, of linear trends, of differences among linearregression slopes and intercepts, of outlying data, and of outliers among data fit by linear regression were assessed, respectively, by 2-tail t-test, by 2 -tail t-test for non-zero linear regression slope, by analysis of covariance (ANOCOVAR), by 2-tail F-test for reduced variance, and by F-test for reduced goodness of linear fit (Snedecor and Cochran, 1989). In cases of unequal variance assessed by 2 -tail F-test using a critical value of $\square=0 . .05$, significance of a difference in means was assessed using Welch's approximate 2-tail t-test (Kendall and Stuart, 1979). P-values obtained for related sets of multiple tests (e.g., region-specific regression slopes for events plotted against period) were transformed to corresponding adjusted values ( $\left.\mathrm{p}_{\text {adj }}\right)$ to 
account for multiple independent tests using Hommel's Bonferroni-type adjustment (Wright, 1992). Significance of the difference between empirical distributions for two samples each of size $\geq 100$ was assessed using Smirnov's approximate Kolmogorov 2-sample test (Kim, 1969).

The relative value of focusing preventive efforts on extreme events that yield very many victims requires knowledge of the extent to which such extreme events may contribute disproportionately to the total number of victims. The Lorenz curve, and corresponding Gini coefficient $(G)$ of disparity are typically used to characterize income and resource inequality in econometric and ecologic studies. A Lorenz curve $C$ plots the inverse cumulative relative frequency function for $n$ ordered relative magnitudes, $f_{i}=x_{(i)} / \square x_{i}, i=1, \ldots, n$, and so plots (vs. $i / n$ ) the cumulative relative contribution of $x_{(i)}$ toward the $n$-sample mean value of $x$, for which an unbiased sample estimate of the corresponding inequality index $G$ is given by $[n /(n-1)][1-$ $\left.\left(\mathrm{A}_{C} / 2\right)\right]$ where $\mathrm{A}_{C}$ is the area beneath $C$ (Dagum, 1980; Damgaard and Weiner, 2000). These measures were used to characterize the relative contribution of extreme events toward total deaths and total casualties due to terrorism over the entire study period.

If generated by a homogeneous independent stochastic process, extreme values of a rate $(X)$ of victims (deaths or casualties) per event are expected to have a generalized extreme value (GEV) distribution, such that the corresponding likelihood of exceedance above a selected threshold $u$ will follow a generalized Pareto (GP) distribution,

$$
\left.\operatorname{Prob}(X>x)=f_{u}\{1+\square(x-u) / \square]\right\}^{-1 / \square} \sqcup \text { 伅 }
$$

where $f_{u}=\operatorname{Prob}(X>u) ; \square$ and $\square$ are the GP-model scale and shape parameters, respectively; and a further Poisson assumption implies that the level $x_{m}$ exceeded on average once every $m$ events or observations is just $x_{m} \mid\left\{\operatorname{Prob}\left(X>x_{m}\right)=1-P_{0}\right\}$, where $P_{0}=\operatorname{Prob}$ (zero exceedances) $\square$ the mean threshold-exceedance rate of $\square=1 / m$ (Coles, 2001; Coles and Pericchi, 2003). A time- 
dependent GP model was also applied in which the scale parameter $\square$ in Eq. (1) was re-expressed as a linear function $\square+\square t$ of time $t$ (Coles, 2001), where $t=Y-1968$ for event year $Y$. Maximum likelihood estimates were obtained for GP-model parameters, together with corresponding profile-likelihood (as feasible, otherwise delta-method) confidence limits (CL); CLs on maximum likelihood estimates of return levels $x_{m} \mid u$ were calculated using the delta method (Coles, 2001). Likelihood equations were modified to reflect an exact Poisson assumption that $P_{0}=\exp (-\square)$. Each GP fit included a likelihood ratio test of the null hypothesis that $\square=0$, and significance value $\mathrm{p}_{\square=0}$ of the corresponding deviance statistic for that test (Coles, 2001). GP fits were obtained conditional on $\square=0$ in each case the corresponding initial fit yielded $\mathrm{p}_{[\neq 0}>0.01$.

Data analysis and model fitting was done using Mathematica $^{\circledR} 5.0$ (Wolfram Research, Champaign, IL) and related computer software (Wolfram, 1999; Bogen, 2004).

\section{Results}

Weapons and targets. Occurrence rates and impacts on morbidity and mortality of all 25,303 events included in the database studied are summarized by period in Table 1, by weapon type for all regions combined in Table 2, and by weapon type for Israel in Table 3. In all regions combined over the entire period studied, $\sim 80 \%$ of adverse events and related casualties, and $\sim 70 \%$ of related deaths involved bombs and guns (Table 2). While bombs caused about 5 times

as many casualties and twice as many deaths as did guns, adverse events involving guns have on average been about $\sim 2.5$ times more lethal those involving bombs (Table 2). The fatal fraction $\left(F_{\text {fat }}\right)$ of all casualties from adverse events was greatest (nearly $\left.80 \%\right)$ for the "other" weapons category (Table 2), which for example includes all terror-related 3,056 deaths on Sept. 11, 2001, 
in New York City, in Washington D.C. and on hijacked American Airlines Flight 77, which had a combined $100 \%$ fatality rate.

Weapon-specific morbidity and mortality rates from events in Israel (Table 3) differ substantially from those in all other regions combined. In Israel from 1968-2004, bombs and guns were involved in only $\sim 75 \%$ of adverse events, but accounted for $>90 \%$ of related casualties and $\sim 86 \%$ of related deaths (Table 3 ). In Israel during this period, bombs caused about 10 times as many casualties and 8 times as many deaths as did guns (i.e., the bomb-to-gun potency ratio in Israel has been about twice that of all other regions combined); and while each adverse event involving guns was on average about twice as lethal as those involving bombs, casualty-weighted fatal fraction $\left(F_{\text {fat }}\right)$ of all casualties by guns and that by bombs were nearly equal (Table 3). The latter fraction for gun-related events in Israel $\left(F_{\text {fat }}=17.5 \%\right)$ is approximately one third the size of the corresponding fraction $(51.2 \%)$ for all other regions combined (Tables 2-3). The percent of total terrorism-induced deaths due to bombs from 19682004 in Israel vs. all other regions combined was $77.1 \%$ vs. $48.1 \%$, whereas this comparison for guns is $9.3 \%$ vs. $22.9 \%$. The Israeli figure for bombs is the greater than that of any other region (the Near East coming in second at $71.0 \%$, and North America last at 10.3\%). Only North America has experienced a percent of gun-induced terrorism-related deaths (1.2\%) smaller than that of Israel.

A few period-specific rates by weapon and target clearly changed starting in 1998, likely reflecting the inclusion of domestic events in the database starting in 1998. For example, periodspecific fractions of events prior to 1998 vs. after 1997, respectively, were for events involving: guns $<40$ vs. $>40 \%$, unspecified weapons $>13 \%$ vs. $<13 \%$, private citizens/property $<9 \%$ vs. $>22 \%$, government targets $<3 \%$ vs. $>20 \%$, and police targets $<2 \%$ vs. $>6 \%$. Some significant 
overall trends were detected, however. Period-specific fractions of events over 5-y periods starting in 1968 through 1997 or through 2007, had the following statistically significant trends: those involving bombs fell from 57\% to $40 \%$ through $1997\left(\mathrm{R}^{2}=0.67, \mathrm{p}=0.046\right)$ and through $2007\left(\mathrm{R}^{2}=0.58, \mathrm{p}=0.029\right)$; those involving diplomatic targets fell from $40 \%$ to $>10 \%$ through $1997\left(R^{2}=0.96, p=0.000024\right)$ and to $<2 \%$ through $2007\left(R^{2}=0.95, p=0.00092\right)$; and those involving airport/airline targets fell from $14 \%$ to $2 \%$ through $1997\left(R^{2}=0.96, p=0.000020\right)$ and to $<0.5 \%$ through $2007\left(\mathrm{R}^{2}=0.96, \mathrm{p}=0.00062\right)$. Similarly significant temporal trends were not observed for corresponding attributable fractions of total casualties or deaths.

Occurrence of total vs. adverse events. No significant trend was found in the occurrence rate of international events worldwide over six 5-y periods (a total of 30 years) from 1968-97 $(p=0.16)$, which corresponds to an average $( \pm 1$ SEM $)$ rate of $274 \pm 31.8$ events $/ y$. The corresponding mean post-1997 rate has been $1707 \pm 118$ events/y - a rate significantly (6.2-fold) greater than the pre-1998 rate $\left(\mathrm{p}=2 \square 10^{-6}\right)$, clearly reflecting the post-1997 inclusion of domestic terrorism events in the MIPT database. There was a significant upward temporal linear trend in adverse event (AE) occurrence worldwide (Figure 1A), though not at a regional level ( $\mathrm{p}_{\mathrm{adj}}>0.05$ ). AE occurrence after 1997 has been approximately 2 - and 4.7-fold greater than those prior to 1998 in Israel and in all other regions combined, respectively, due to post-1997 inclusion of domestic events in RAND-MIPT data. Using these approximations, corresponding cumulative AEs by year $y$ were found to be well approximated by linear-quadratic functions: $A_{\mathrm{IS}}(y)=11.478( \pm 0.646) Y+0.24515( \pm 0.02284) Y^{2}\left(\right.$ Israel, $\left.\mathrm{R}^{2}=0.992\right)$ and $A_{\mathrm{OR}}(y)=$ $204.055( \pm 12.272) Y+6.3435( \pm 0.4341) Y^{2}$ (all other regions, $\left.\mathrm{R}^{2}=0.994\right)$, with $Y=y-1968$, 
coefficient estimates shown $\pm 1 \mathrm{SE}$, and each $\mathrm{R}^{2}$ calculated as the complement of the corresponding residual-to-total sum-of-squares ratio.

Significant upward temporal trends have occurred also in the worldwide "adverse" fraction $\left(F_{\text {adv }}\right)$ of period-specific terrorist events in Africa, Latin America, the Near East (excluding Israel and the Occupied Territories), and South Asia taken as a "rising" group (Figure 1B). However, no trend is evident in $F_{\text {adv }}$ for Israel, or for all other regions combined as a "static" group (Figure 1B). Over all periods studied, Israel experienced the highest mean value of $F_{\text {adv }}(0.60)$, about twice that of the "static" regional group, while over this time span the "rising" group has experienced $F_{\text {adv }}$ levels that increased from about that of the "static" group to about that of Israel (Figure 1B).

Victim, victims/event and fatality rates. Worldwide casualties and deaths per period due to terrorism have risen fairly steadily over the entire time span studied, with pre-1998 levels (which did not include domestic events), having been about 4-fold less than post-1997 levels (which did; Figure 1C). Corresponding period-specific values of the ratio of total victims to total events show similarly increasing trends, which were not clearly affected by post-1997 inclusion of domestic events (Figure 1D).

Upward temporal trends are also evident in the ratios of casualties and of deaths to total adverse events (AE) (Figure 2A). While casualty-weighted mean values of $F_{\text {fat }}$ by period show no temporal trend in or outside of Israel, unweighted values of $F_{\text {fat }}$ (i.e., death-to-casualty ratios for each event, averaged within each period) have increased steadily over time in all regions combined excluding Israel $(\mathrm{p}=0.011$, Figure $2 \mathrm{~B})$. Integrating over all time periods, the relatively high $F_{\text {fat }}$ ratio for North America compared to all other regions (Figure 2C) is due to 
the $100 \%$ fatality rate for all casualties inflicted on September 1,2001 . The $F_{\text {fat }}$ ratio for Israel is (just) significantly smaller than those of all other regions excluding North America $(\mathrm{p}=0.05)$.

No single event explains Israel's relatively low casualty-weighted mean $F_{\text {fat }}$ ratio (Figure 2B-C). Although, $F_{\text {adv }}$ generally has been higher for Israel than for any other region examined (Figure 1B), corresponding period-specific deaths/event for Israel vs. other regions combined show (by ANOCOVAR) no significant difference in either slope $(\mathrm{p}=0.32)$ or intercept $(p=0.090)$ of linear trend. The latter trend was significantly positive for the other combined regions $\left(\mathrm{p}_{\text {adj }}=0.0016\right)$, increasing from approximately 0.4 to 1.6 deaths/event from the first to the last time period examined. Israel's casualty-weighted mean $F_{\text {fat }}$ ratio has remained about half that of other regions combined (Figure 2B-C).

Period-specific worldwide $F_{\text {fat }}$ distributions clearly have shifted to the right over time, increasingly including more extreme values (Figure 3). For example, from 1968-72 to 20032004, the median value of $F_{\text {fat }}$ increased 0.14 to 0.50 , while the percentage of events in which $F_{\text {fat }}=0$ decreased from $41 \%$ to $27 \%$ (Figure 8 ). During the same period in Israel, $F_{\text {fat }}$ values for adverse events involving bombs have been lower, and $F_{\text {fat }}$ values for adverse events involving guns have been remarkably lower, than corresponding $F_{\text {fat }}$ values experienced in all other regions combined, regardless of the casualties/AE rate (Figure 4A). Likewise, the percent of gun-related lethal events has been substantially lower in Israel compared to other combined regions, regardless of the number of deaths per lethal event (Figure 4B).

Per capita risks of mortality and morbidity from terrorism. Combined over all periods examined, events in Israel have tended to involve greater numbers of victims per event than have events that occurred in all other regions combined (Figure 5). During this interval, while the 
Israeli population comprised an average of $0.093 \%$ of the population of all other regions combined, RAND-MIPT-TC data indicate that Israel hosted $4.0 \%$ of all terrorist events, $5.3 \%$ of all terrorism-related deaths, and $9.7 \%$ of all terrorism-related casualties (i.e., about 40, 60 and 100 times the corresponding rates expected based solely on relative population).

Israel similarly has experienced far greater per capita lifetime (70-year) equivalent risks of mortality $\left(R_{\text {fat }}\right)$ and morbidity $\left(R_{\text {cas }}\right)$ due to terrorism over this period, compared to all other nonNear-Eastern regions combined (Figure 6). From 1968-1997 (prior to inclusion of domestic events in the data analyzed), $R_{\text {cas }}$ and $R_{\text {fat }}$ had mean values of 2,400 per million $(\sim 0.2 \%)$ and 410 per million ( $\sim 0.04 \%)$, respectively - values 190- and 150-fold greater, respectively, than corresponding risks experienced during the same period in all other non-Near-Eastern regions combined. Corresponding levels of per capita risk experienced in the Near East outside of Israel and the Occupied Territories over all periods have ranged between levels experienced in Israel and those experienced in non-Near-Eastern regions, while rates experienced in the Occupied Territories remained at Near-Eastern levels from 1968-92 but then jumped approximately to Israeli levels thereafter (Figure 6).

Extreme values of victims/event. Lorenz curves for the cumulative fraction of victims of terrorist events during 1968-2004 (Figure 7) indicate substantial heterogeneity in victim/event rates in Israel ( $G=0.600$ for deaths, 0.689 for casualties), and even more so in all other regions combined ( $G=0.717$ for deaths, 0.796 for casualties). The Lorenz curves for each region also have quite different upper-right patterns, indicating very different contributions to victim totals by extreme events that caused the greatest numbers of victims (Figure 7). For example, from these curves it is evident that during this period that the top $10 \%$ of events in Israel ranked by 
harmfulness caused about half of all victims there, whereas about half of all victims were caused by the top $2.5 \%$ of all similarly ranked events in all other regions combined.

Absent any clear indication of a pre-1998 vs. post-1997 discontinuity (e.g., due to post-1997 inclusion of domestic terrorist events) in data on victims/event, on victims per adverse event, or on the fatal fraction of adverse events (Figures 1B, 1D, 2A-B), events during 1968-2004 that yielded $\geq 1$ victim (casualty or death) were pooled for the purpose of extreme-value analysis. Generalized Pareto (GP) models were found to be reasonably good models of extreme-value patterns exhibited in Israeli and Other-Region data on casualties/AE, and for Other-Region data on deaths per lethal event (Figure 8, left plots). Corresponding model parameter estimates and confidence limits are listed in Table 4 (rows 1, 3, 4 and 6). In view of significant temporal trends in worldwide victims/event data (Figure 1D), fits using a GP-trend model were made to nonIsraeli per event data on deaths and on casualties; however, neither fit included a trend $(\square)$ parameter estimate significantly different from zero (Table 4, rows 2 and 5).

The fits obtained for Israeli vs. combined non-Israeli regions clearly differ markedly. In view of similarly marked differences in the fatality and relative frequency of gun- vs. bombrelated adverse or fatal incidents in Israel vs. all other regions combined (Figure 6), additional weapon-specific GP-model fits were obtained shown in Figure 8 (right plots), for which corresponding parameter estimates and confidence limits are listed in Table 4 (rows 7-14). These additional fits similarly characterize the extreme-value data on victims/event reasonably well, with shape parameter ( $\square$ values estimated to be either $\sim 0$ (notably, for all fits involving gun- or bomb-related deaths) or significantly $<0$ (most notably for fits involving gun- or bombrelated casualties in Israel), and in no case significantly $>0$. The weapon-specific fits obtained 
for Israeli vs. combined non-Israeli regions clearly differ markedly for data on bomb-related deaths and casualties and on gun-related casualties.

Estimated cumulative AE-occurrence functions $A_{\mathrm{IS}}(y)$ and $A_{\mathrm{OR}}(y)$ given above (Occurrence of total vs. adverse events) were used to re-scale region-specific abscissa values of the GP-model fits shown in Figure 8 (left), resulting in the re-scaled fits (and 95\% CL) shown in Figure 9 that are extrapolated to the year 2080 and compared to corresponding empirical data through 2004 . These fits represent region-specific forecasts of the maximum value $\mathrm{MV}(y)$ of victims/AE expected by the indicated year $y$, arising from terror-related events involving all (i.e., only those) weapons already represented in RAND-MIPT data through 2004. For example, the top plot in Figure 9 indicates that the likelihood of a terror-related event that involves one of these weapons causing $\sim 10,000$ casualties somewhere outside Israel becomes significant (2-tail $\mathrm{p}>0.05$ ) by around the year 2025. Note the forecasts shown were not fit to the corresponding annualsummary data subsets also plotted, but rather are temporal projections of GP-model fits from Figure 8 (left) that were made to time-independent, victim-number data for (in Israel) hundreds or (in all other regions combined) thousands of individual adverse events. Expected values of the maximum mortality/AE rate exceed those of the maximum rate of total casualties/AE after the year 2020 , but this apparent inconsistency may be due to greater uncertainty in forecasts of the latter measure compared to the former.

An important aspect of each forecast in Figure 9 involves the steadily decreasing value of its expected excess relative magnitude $\operatorname{ERM}(y, \mathrm{~d} y)=\{[\operatorname{MV}(y) / \operatorname{MV}(y-\mathrm{d} y)]-1\} 100 \%$ after a lag period of $\mathrm{d} y$ years relative to any current year $y$. Setting $\mathrm{d} y=10$ years, for example, $\operatorname{ERM}(y, 10)$ for worldwide deaths/AE outside Israel decreases from about $100 \%$ in 1990 , to $60 \%$ in 2000 , to $20 \%$ in 2060 , whereas $\operatorname{ERM}(y, 10)$ for worldwide casualties/AE outside Israel decreases from 
about $50 \%$ in 1990 , to $30 \%$ in 2000 , to $10 \%$ in 2045 . A similar decreasing $\operatorname{ERM}(y, 10)$ pattern pertains to Israel. The forecasts quantify an expectation of increasing difficulty faced by terrorists who seek to use the current array of weapons to cause harm that is substantially larger in relative magnitude than the most harmful event experienced over a specified previous period of time.

\section{Discussion}

A number of statistically significant temporal trends were identified in RAND-MIPT-TC data on international terrorist events from 1968-1997, including trends for adverse events, the adverse fraction of all events, total victims, victims/event, and unweighted fatal fraction of adverse events. Most of these significant trends pertain also to the larger period 1968-2004, which includes the post-1997 period during which domestic events were included in the data analyzed. An increased lethality trend, observed in many previous studies on terrorism (Frey and Leuchinger, 2003), has been attributed to the increasing proportion of fundamentalist religionbased terrorist groups seeking mass casualties of innocent people to make their cause widely known, in contrast to leftist/nationalist terrorists who prefer to persuade hearts and minds toward revolution by avoiding the death or injury of people not directly connected with an existing political and economic regime (Hoffman 1997, 1998; Juergensmeyer, 1997).

The data analyzed clearly indicate a persistent, relatively very high mortality and morbidity burden faced by Israel from terrorism during 1968-2004, compared to all other regions combined. Lifetime (70-year) equivalent risks of casualty estimated in this study to be between $10^{-3}$ and $10^{-2}$, and corresponding mortality risks between $10^{-4}$ and $10^{-3}$, approach or exceed corresponding occupational hazard levels for industrial workers in economically advanced 
nations. In contrast, corresponding lifetime casualty risks between $10^{-6}$ and $10^{-4}$ and mortality risks between $10^{-6}$ and $2 \square 10^{-5}$ experienced in non-Near-Eastern regions are risk levels that, in a public health context, are typically considered de minimis. RAND-MIPT-TC data do, however, exhibit the significant upward temporal trend noted in log-casualty rates for most of the world, that have increased by about two orders of magnitude over 40 years (Figure 6). Any public health significance of this trend can only be assessed in the broader context of lifetime risks of casualty from all forms of organized human violence, accounting for changes over time in how such violence has been defined and classified (e.g., as war, civil war, revolution, crime or “terrorism").

In contrast to the relatively high risk burden faced by Israel during 1968-2004, the RANDMIPT-TC data also clearly indicate a persistent, relatively low fatal fraction of terrorism-related casualties (particularly for gun-related casualties) in Israel compared to all other regions combined. Relatively low $F_{\text {fat }}$ values in Israel might possibly be explained by erroneous inflation of casualty rates (e.g., due to greater tendency to seek medical attention for minor or non-existent injuries, compared to other areas worldwide), although the authors are not aware of any evidence supporting this hypothesis. In contrast, a key factor likely to contribute to lower $F_{\text {fat }}$ values in Israel compared to other regions is the very effective, integrated system of world-renowned and remarkably successful emergency medical research and services developed over many decades in Israel, in part due to its adaptive response to casualties generated by persistent terrorism there. In addition to its integrated delivery system, emergency medical services in Israel have benefited from related highly effective technologies developed in that country over the last decade, such as the emergency "Israeli bandage" that since 2002 has become standard equipment in many U.S. military and law-enforcement organizations, due to its ability to provide easily administered, 
immediate hemorrhage control, and so prevent death from shock before other treatment is possible (Blackburn, 2005). Israeli emergency medical system has increased survival among all (terror- and non-terror-related) severe trauma patients over time, though experience treating terror-related trauma there has shown these injuries to involve greater risk of death, greater involvement of younger victims, more serious and extensive burns, more penetrating injuries, greater vascular damage, greater requirement for surgery, and greater risk of very serious longterm disability and rehabilitation than in cases unrelated to terrorism (Aharonson-Daniel et al., 2003; Paleg and Aharonson-Daniel, 2004; Paleg et al., 2003, 2004). While the Israeli emergency medical system has been shown to be increasingly effective in recent years at reducing mortality associated with terror-related injuries, relatively low $F_{\text {fat }}$ values for Israel compared to all other regions combined have shown no evidence of a temporal trend over the last four decades (Figure 6B). Thus, the primary factor explaining this difference must lie in the combination of a greater fraction of bomb- vs. gun-related casualties, together with lesser $F_{\text {fat }}$ values for both bombs and guns, in Israel compared to all other regions combined.

Marked heterogeneity in event harmfulness exhibited in RAND-MIPT-TC data (Figure 7) clearly indicates the relative importance of extremely harmful events in contributing to victim totals, and so highlights the potential importance of better understanding extreme-value behavior in victim/event rates associated with terrorism. Regularity in weapon-specific extreme-value patterns for victims/event appear to be described well by Pareto (or nearly Pareto) distributions (i.e., generalized Pareto distributions with shape parameters equal or nearly equal to zero) for six of eight region/weapon/endpoint combinations examined, and to be described reasonably well by generalized Pareto distributions with a substantially negative shape parameter in the cases of gun and bomb-related casualties in Israel (Table 4, Figure 8). 
The extreme-value behavior exhibited in RAND-MIPT-TC victims/event data appears to be consistent with patterns expected for independent occurrences of phenomena that have common underlying mechanisms. Regularity in these patterns indicates that extreme variations in public health impacts of terrorist events worldwide are as predictable as variations in extreme values physical phenomena such as forest fires, rainfall, earthquakes, and the like. The fact that GPmodel fits obtained in this study reflect shape parameters that are approximately zero or are negative, but not substantially positive, is quite interesting. Just this type of constraint on extreme-value behavior is predicted generally for complex systems in which failure tolerances have been optimized to limit predictable losses conditional on resource constraints and on specified levels of risk aversion. Complex systems that trade off resource allocations and losses to achieve highly optimized tolerance (HOT) using a risk-neutral strategy are robust to common perturbations but susceptible to rare ones, and so exhibit "fragile" extreme-loss-event distributions characterized by "heavy" upper-tail with likelihoods that decrease at an exponential (first-order) rate proportional to the value (or logarithm) of the corresponding cost or loss to the system (Doyle and Carlson, 2000; Zhou and Carlson, 2000; Carlson and Doyle, 2002). HOT models thus exhibit just the kind of extreme-value behavior that is predicted by a Pareto model (i.e., a GP model with a shape parameter equal to zero). Risk aversion expressed in systems that are more intolerant of high losses by constraining values (or log) of any extreme loss to increase only as a sub-linear function of its negative log-likelihood (Newman et al., 2002). Systems that optimize resources to constrain losses in a risk averse manner thus have the same extreme-value behavior as GP models with a negative shape parameter. The fact that most victims/event patterns for combined regions outside Israel were found to show little to no risk-averse characteristic (Figure 8) indicates that exploitation of terror opportunities has occurred in a 
relatively unconstrained fashion, which in turn underscores the virtual inevitability of rare but very catastrophic consequences if current management strategies are not revised fundamentally.

Extreme value patterns found in this study of RAND-MIPT-TC data provide a fairly reliable empirical basis to improve strategic plans that address the risks and consequences of terrorism. Strategies from improved insurance mechanisms (e.g., Kunreuther, 2002) to more efficient counter-measure targeting could take better advantage of trend information contained in such data. For example, results from the present study suggest that historical data on extreme victims/event rates can predict time-integrated mortality or morbidity impacts of future terrorist events (Figures 8 and 9). Such predictions are consistent with a recently precipitous and continuing decline in excess relative magnitude of maximum harm expected per adverse terror event. In other words, terrorists who use the current array of weapons to surpass previous levels of harm by notable relative amounts are increasingly likely to face failure and frustration. A likely and ominous consequence is that terrorist interest in switching to novel weapons or approaches with much greater destructive power is now near its peak. These observations support a renewed and urgent emphasis on worldwide development, deployment and coordination of effective counter-measures to prevent, detect and thwart terrorist applications of such novel weapons.

Although internal consistencies and statistical strengths of patterns and trends identified in this study support the conclusion that meaningful predictive interpretations of RAND-MIPT-TC data are currently possible, some important caveats need to be considered. Conclusions based on apparent patterns and trends identified in this study clearly are conditional on the reliability of the data analyzed. These data have many potential sources of bias or error that merit careful consideration, including (by no means exhaustively): ambiguity or inconsistency in the 
definition of events included vs. excluded from the database; records that may be missing or incomplete due to ongoing database management; data missing due to lack of records or media coverage; and perhaps most importantly, primary reliance on unconfirmed or potentially biased or potentially inaccurate reports by local news media. Some of the patterns and trends observed in the present study are highly significant statistically, and thus are not likely to be artifacts due to isolated errors or omissions concerning small numbers of particular incident records.

However, any pervasive systematic biases that may be present in the data studied could have important confounding effects that remain difficult to assess.

Insofar as initial news-media reports of terrorist events appear to have been the primary source of input to RAND-MIPT data, a key source of potential bias reflected in these data would be the fact that such reports may reflect inaccurate initial "guess-timates" of total injuries and/or deaths by local reporters, or even politically motivated distortion of true victim counts in regions that lack independent news media. Corrections or refinements to initial news accounts may or may not appear in subsequent media reports, and if any do appear, it is not clear what if any systematic RAND-MIPT efforts are made to update previous records. Evidence for non-random bias in RAND-MIPT data appears in Figure 3, in which each cumulative distribution shown has a substantial jump in relative frequency (ordinate) at corresponding $F_{\text {fat }}$ (abscissa) values equal precisely to one third and to one half. These jumps clearly reflect incorporation of crude initial estimates of the fatal fraction of casualties estimated for each event, rather than estimates based on confirmed hospital records or other more reliable data sources.

Hospital records are available in the case of Israel, which administers an Israel National Trauma Registry of all hospitalizations for physical trauma at nine Israeli trauma centers (including six level-1 centers) that are part of a tertiary care and referral system that receive the 
majority of severe or complicated cases of physical injury throughout Israel; this Registry tracks, among other things, in-hospital deaths and whether each incident is related to terrorism (Aharonson-Daniel et al., 2003). Between November 1, 2000, and June 30, 2003, this Registry recorded 1,661 terror-related injuries resulting in 100 in-hospital deaths (Paleg and AharonsonDaniel, 2004). Over the same period in Israel, the RAND-MIPT data include a total of 3,353 casualties including 2,861 injuries and 494 deaths. One source of these discrepancies may be that initial casualty estimates made by Israeli (and perhaps most local) media and entered into RAND-MIPT data tend to overestimate actual casualties. It is also likely that RAND-MIPT data include estimates of people not covered in the National Trauma Registry, who include those with relatively minor injuries that did not require hospitalization, deaths at the scene of events or on hospital arrival, and/or outpatient deaths that occurred subsequent to hospitalization (AharonsonDaniel et al., 2003). In cases where accurate records of terrorism-related casualties can be reconstructed, systematic comparison of such information with RAND-MIPT data would help clarify the source of any discrepancies and perhaps also the extent to which these may pertain to other parts of RAND-MIPT data.

Despite potential data limitations, a number of patterns and trends were identified in this study concerning mortality and morbidity from terror-related events worldwide. Some of these appear to have predictive value that may be used to improve current or planned systems for preventing and managing consequences of terror-related events. Early public release and broader analysis of emerging data will likely facilitate the design of more effective strategies to manage terror-related risks. 
Acknowledgements - This work was performed under auspices of the U.S. Department of Energy by University of California, Lawrence Livermore National Laboratory (LLNL) under Contract W-7405-Eng-48, with support from the LLNL Risk and Response Management Program. We

are grateful for insights and suggestions provided by Steven E. James and an anonymous reviewer pertaining to this work.

\section{References}

Aharonson-Daniel, L, Y Waisman, YL Dannon, and K Peleg. 2003. Epidemiology of terrorrelated versus non-terror-related traumatic injury in children. Pediatrics 112 (4), e280.

Blackburn, N. 2005. Israeli innovative bandages saving American lives in Iraq. Israel21c (www.israel21c.org) Jan. 9, 2005.

Bogen, KT. 2002. RiskQ 4.2: An Interactive Approach to Probability, Uncertainty and Statistics for use with Mathematica ${ }^{\circledast}$. UCRL-MA-110232 Rev. 3. Lawrence Livermore National Laboratory, Livermore, CA.

Carlson, JM, and J Doyle. 2002. Complexity and robustness. Proc. Natl. Acad. Sci. USA (PNAS) 99, 2538-2545.

Snedecor, GW, and WG Cochran. 1989. Statistical Methods. 8th ed. Iowa State University Press, Ames, IA.

Coles, S 2001. An Introduction to Statistical Modeling of Extreme Values. Springer-Verlag, London, UK, pp. 18-44, 74-91,105-123.

Coles, S, and L Pericchi. 2003. Anticipating catastrophes through extreme value modelling. $J$. Roy. Statist. Soc. Series C (Appl. Statist.) 52, 405-416.

Congleton, R. 2002. Terrorism, interest-group politics, and public policy: curtailing criminal modes of political speech. Independ. Rev. 7(1), $28 \mathrm{p}$. http://www.independent.org/publications/tir/article.asp?issueID=16\&articleID=118 . 
Cordes, B, B Hoffman, BM Jenkins, K Kellen, SE Moran, and WF Sater. 1984. Trends in International Terrorism, 1982 and 1983. R-3183-SL, August 1984. Rand Corporation, Santa Monica, California (http://www.rand.org/publications/R/R3183/).

Dagum, C. 1980. Inequality measures between income distributions with applications.

Econometrica 48, 1791-1803.

Damgaard, C, and Weiner, J. 2000. Describing inequality in plant size or fecundity. Ecology 81, 1139-1142.

Doyle, J, and JM Carlson. 2000. Power laws, highly optimized tolerance, and generalized source coding. Phys. Rev. Lett. 84, 5656-5659.

Ellis, JO. 2004. MIPT: Sharing terrorism information resources. Intelligence and Security Informatics, Proceedings Lecture Notes in Computer Science 3073, 520-525.

Fowler. W. W. (1981). Terrorism Data Bases: A Comparison of Missions, Methods, and Systems. N-1503-RC, March 1981. Rand Corporation, Santa Monica, CA (http://www.rand.org/publications/N/N1503/).

Frey, BS, and S Leuchinger. 2003. Measuring terrorism. Institute for Empirical Research in Economics University of Zurich Working Paper Series (ISSN 1424-0459), Working Paper No. 171, October 2003.

Hoffman, B. 1997. The confluence of international and domestic trends in terrorism. Terrorism and Political Violence 9, 1-15.

Hoffman, B. 1998. Inside Terrorism. Colombia University Press. New York, NY.

Juergensmeyer, M. 1997. Terror mandated by God. Terrorism and Political Violence 9, 16-23.

Kendall, M, and A Stuart. 1979. The Advanced Theory of Statistics, Vol. 2: Inference and Relationship. 4th ed. MacMillan Publishing Co., NY, pp. 159-60.

Kunreuther, H. 2002. The role of insurance in managing extreme events: implications for terrorism coverage. Risk Anal. 22, 427-437. 
Kim, PJ. 1969. On the exact and approximate sampling distribution of the two sample Kolmogorov-Smirnov criterion $\mathrm{D}_{\mathrm{mn}}, \mathrm{m} \leq \mathrm{n}$. J. Am. Statist. Assoc. 64, 1625-1637.

Memorial Institute for the Prevention of Terrorism (MIPT). 2004a. MIPT Terrorism Knowledge Base: A Comprehensive Databank of Terrorist Incidents and Organizations. Incident data updated November 24, 2004. http://www.tkb.org/Home.jsp.

Memorial Institute for the Prevention of Terrorism (MIPT). 2004b. Understanding the terrorism database. MIPT Quart. Bull. $1^{\text {st }}$ quarter 2002 (www.mipt.org/MIPT-Bulletins.asp), 4-6.

Memorial Institute for the Prevention of Terrorism (MIPT). 2004c. RAND Terrorism Chronology 1968-1997 and RAND ${ }^{\circledR}$-MIPT Terrorism Incident database (1998-Present). Incident data updated November 24, 2004. http://www.tkb.org/RandSummary.jsp.

Newman, MEJ, M Girvan, and JD Farmer. 2002. Optimal design, robustness, and risk aversion. Phys. Rev. Lett. 89, 028301-1 - 028301-4.

Peleg, K, L Aharonson-Daniel, M Michael, and SC Shapira. 2003. Patterns of injury in hospitalized terrorist victims. Am. J. Emergency Med. 21, 258-262.

Peleg, K, L Aharonson-Daniel, M Stein, Y Kluger, M Michaelson, A Rivkind, and V Boyko. 2004. Increased survival among severe trauma patients. Arch. Surg. 139, 1231-1236.

Peleg, K, and L Aharonson-Daniel. 2004. Epidemiology of terror related injuries. Abstract 4199.0. American Public Health Association (APHA), 132 nd Annual Meeting ("Public Health and the Environment"), Washington, DC, Nov. 6-10, 2004.

Smithson, AE. 2000a. Chapter 2: Grounding the threat in reality. In: AE Smithson and L-A Levy, Ataxia: The Chemical and Biological Terrorism Threat and the U.S. Response. Report No. 35, October 2000. The Henry L. Stimson Center, Washington, DC, pp. 11-69.

Smithson, AE. 2000b. Chapter 3: Rethinking the lessons of Tokyo. In: AE Smithson and L-A Levy, Ataxia: The Chemical and Biological Terrorism Threat and the U.S. Response. Report No. 35, October 2000. The Henry L. Stimson Center, Washington, DC, pp. 71-111. 
U.S. Bureau of the Census (USBC). International Data Base. 2004. Total Midyear Population for the World: 1950-2050. Data updated 9-30-2004. year Population for the World: 1950-2050. http://www.census.gov/ipc/www/worldpop.html .

Wolfram S. 1999. Mathematica Book, 4th ed. Cambridge University Press: Cambridge, UK.

Wright, S.P. 1992. Adjusted p-values for simultaneous inference. Biometrics 48, 1005-1013.

Zhou, T, and JM Carlson. 2000. Dynamics and changing environments in highly optimized tolerance. Phys. Rev. E 62, 3197-3204. 


\section{Tables}

Table 1. Summary of RAND-MITP-TC data on worldwide terrorist events, by period. ${ }^{a}$

\begin{tabular}{|ccccccc|}
\hline & $\begin{array}{c}\text { Events } \\
\text { Period }^{a}\end{array}$ & $\begin{array}{c}\text { Adverse } \\
\text { events } \\
(n)\end{array}$ & $\begin{array}{c}F_{\text {adv }}=n / e \\
(\%)\end{array}$ & $\begin{array}{c}\text { Injuries }^{b} \\
(c-m)\end{array}$ & $\begin{array}{c}\text { Deaths } \\
(m)\end{array}$ & $\begin{array}{c}F_{\text {fat }}=m / c \\
(\%)\end{array}$ \\
\hline 1970 & 760 & 135 & 17.8 & 665 & 385 & 36.7 \\
1975 & 1,201 & 319 & 26.6 & 1,827 & 855 & 31.9 \\
1980 & 1,390 & 480 & 34.5 & 3,509 & 1,193 & 25.4 \\
1985 & 1,831 & 629 & 34.4 & 5,029 & 2,308 & 31.5 \\
1990 & 1,747 & 548 & 31.4 & 3,442 & 1,713 & 33.2 \\
1995 & 1,301 & 545 & 41.9 & 8,887 & 2,003 & 18.4 \\
$2000^{a}$ & 7,948 & 3,030 & 38.1 & 23,642 & 11,154 & 32.1 \\
$2005^{a}$ & 9,125 & $4,287.5$ & 47.0 & $35,397.5$ & $14,492.5$ & 29.0 \\
\hline All 40 yrs $^{2}$ & 25,303 & $9,973.5$ & 39.4 & $82,398.5$ & $34,103.5$ & 29.3 \\
\hline
\end{tabular}

${ }^{a}$ Periods are named by midpoint of a corresponding 5-year interval, starting with $1968-1972$ and ending with 2003 - 2007. Values listed for 2000 and 2005 include "domestic" terrorism events, whereas data for earlier periods do not. Projected totals listed for $2003-2007$ were estimated by linear extrapolation from data reported for 2003 2004.

${ }^{b}$ Casualties $(c)$ here denotes the sum of the number $(m)$ of persons killed plus the number $(c-m)$ who are non-fatally injured. 
Table 2. Events and consequences in all regions combined, by weapon type. ${ }^{a}$

\begin{tabular}{|c|c|c|c|c|c|c|}
\hline Weapon $^{a}$ & $\begin{array}{c}\% \text { of all } \\
\text { events, } \\
n / E \\
(\%)\end{array}$ & $\begin{array}{c}\% \text { of all } \\
\text { adverse } \\
\text { events, } \\
n / N \\
(\%)\end{array}$ & $\begin{array}{c}\% \text { of all } \\
\text { casualties, } \\
c / \square c \\
(\%)\end{array}$ & $\begin{array}{c}\% \text { of all } \\
\text { deaths, } \\
m / \square m \\
(\%)\end{array}$ & $\begin{array}{l}\text { Unweighted } \\
\text { fatal fraction, } \\
F_{\text {fat }}=\overline{m / n} \\
(\%)\end{array}$ & $\begin{array}{c}\text { Weighted } \\
\text { fatal fraction, } \\
F_{\text {fat }}=\square m / \square n \\
(\%)\end{array}$ \\
\hline Bombs & 53.4 & 41.8 & 70.1 & 48.1 & 24.2 & 20.1 \\
\hline Guns & 19.9 & 36.4 & 13.2 & 23.0 & 65.5 & 51.2 \\
\hline Sharps & 1.3 & 3.3 & 0.67 & 1.2 & 64.4 & 53.9 \\
\hline R-Bombs & 1.9 & 2.4 & 4.7 & 3.2 & 21.3 & 20.1 \\
\hline Fire & 9.8 & 1.6 & 2.7 & 2.7 & 30.5 & 29.4 \\
\hline Chemical & 0.2 & 0.3 & 0.59 & 0.09 & 32.2 & 4.3 \\
\hline Biological & 0.08 & 0.1 & 0.02 & 0.02 & 38.3 & 35.3 \\
\hline Other & 13.3 & 14.1 & 8.1 & 21.7 & 78.2 & 78.9 \\
\hline Tot. or Ave. ${ }^{b}$ & 100.0 & 100.0 & 100.0 & 100.0 & 48.2 & 29.4 \\
\hline
\end{tabular}

${ }^{a}$ Potencies are calculated per adverse event, based on MIPT-RAND-TC data for 1968-2004, involving a total of $\mathrm{E}=$ 19,828 events, $N=7,401$ adverse events, 86,568 casualties and 25,408 deaths. Sharps $=$ knives and other bladed weapons, R-Bombs = remote-control bombs, Chemical $=$ chemical agent(s), Biological $=$ biological agent(s); "Other" includes unknown or unspecified. See Table 1 for definition of other notation. See text concerning temporal trends.

${ }^{b}$ In this row, totals are listed in columns $2-5$ and $c$-weighted average values are listed in columns 6-7. 
Table 3. Events and consequences in Israel, by weapon type. ${ }^{a}$

\begin{tabular}{|lcccccc|}
\hline & $\begin{array}{c}\text { \% of all } \\
\text { events, } \\
n / E\end{array}$ & $\begin{array}{c}\text { \% of all } \\
\text { adverse } \\
\text { events, } \\
n / N\end{array}$ & $\begin{array}{c}\text { \% of all } \\
\text { casualties, } \\
c / \square c\end{array}$ & $\begin{array}{c}\text { \% of all } \\
\text { deaths, } \\
m / \square m \\
\text { Weapon }^{a}\end{array}$ & $\begin{array}{c}\text { Unweighted } \\
\text { fatal fraction, } \\
F_{\text {fat }}=\overline{m / n}\end{array}$ & $\begin{array}{c}\text { Weighted } \\
\text { fatal fraction, } \\
F_{\text {fat }}=\square m / \square n \\
(\%)\end{array}$ \\
\hline Bombs & 62.8 & 59.7 & 84.8 & 77.1 & 16.8 & 14.5 \\
Guns & 13.6 & 15.4 & 8.5 & 9.3 & 35.1 & 17.5 \\
Sharps & 8.2 & 13.9 & 1.5 & 3.3 & 41.2 & 33.1 \\
R-Bombs & 1.7 & 0.9 & $<0.1$ & 0 & 0 & 0 \\
Fire & 5.7 & 0.9 & 0.2 & 0 & 0 & 0 \\
Chemical & 0 & 0 & 0 & 0 & 0 & 0 \\
Biological & 0 & 0 & 0 & 0 & 0 & 0 \\
Other & 8.0 & 9.2 & 5.9 & 10.3 & 49.8 & 33.2 \\
\hline Tot. or Ave. ${ }^{b}$ & 100.0 & 100.0 & 100.0 & 100.0 & 25.8 & 15.9 \\
\hline
\end{tabular}

${ }^{a}$ Potencies are calculated per adverse event, based on MIPT-RAND data for 1968-2004, involving a total of $\mathrm{E}=785$ events, $N=447$ adverse events, 8,374 casualties and 1,334 deaths. See Table 2, note $a$.

${ }^{b}$ In this row, totals are listed in columns 2-5 and $c$-weighted average values are listed in columns 6-7. 
Table 4. Generalized Pareto model fits to MIPT-RAND-TC victims/event data. ${ }^{a}$

\begin{tabular}{|c|c|c|c|c|c|c|}
\hline $\operatorname{Region}^{a}$ & Endpoint $^{b}$ & Weapon $^{b}$ & $u$ & $\begin{array}{c}\prod_{(95 \% \mathrm{CL})^{a}} \\
(9)\end{array}$ & $\begin{array}{c}\Gamma_{1} \\
(95 \% \mathrm{CL})^{a}\end{array}$ & $\mathrm{p}_{[\neq 0}$ \\
\hline Other & Casualty & All & 5 & $\begin{array}{c}0.537 \\
(0.506,0.568)\end{array}$ & $\begin{array}{c}-0.119 \\
(-0.154,-0.077)\end{array}$ & $<10^{-6}$ \\
\hline Other & Casualty & All & 5 & $\begin{array}{c}\Pi=0.578 \\
(0.498,0.665) \\
\hat{\square}=-0.0014 \\
(-0.0042,0.0011)\end{array}$ & $\begin{array}{c}-0.119 \\
(-0.154,-0.077)\end{array}$ & $<10^{-6}$ \\
\hline Israel & Casualty & All & 5 & $\begin{array}{c}1.03 \\
(0.900,1.19)\end{array}$ & $\begin{array}{c}-0.632 \\
(-0.732,-0.534)\end{array}$ & $\sim 0$ \\
\hline Other & Death & All & 20 & $\begin{array}{c}0.365 \\
(0.314,0.428)\end{array}$ & 0 & 0.59 \\
\hline Other & Death & All & 20 & $\begin{array}{c}\Pi=0.463 \\
(0.291,0.698) \\
\hat{\square}=-0.0036 \\
(-0.011,0.0026)\end{array}$ & 0 & 0.75 \\
\hline Israel & Death & All & 10 & $\begin{array}{c}0.241 \\
(0.180,0.334) \\
\end{array}$ & 0 & 0.11 \\
\hline Other & Casualty & Bombs & 20 & $\begin{array}{c}0.429 \\
(0.386,0.475)\end{array}$ & $\begin{array}{c}-0.112 \\
(-0.165,-0.038)\end{array}$ & 0.0052 \\
\hline Israel & Casualty & Bombs & 5 & $\begin{array}{c}1.12 \\
(0.959,1.31)\end{array}$ & $\begin{array}{c}-0.685 \\
(-0.805,-574)\end{array}$ & $\sim 0$ \\
\hline Other & Casualty & Guns & 20 & $\begin{array}{c}0.353 \\
(0.272,0.471)\end{array}$ & 0 & 0.32 \\
\hline Israel & Casualty & Guns & 5 & $\begin{array}{c}1.34 \\
(0.718,2.02 *)\end{array}$ & $\begin{array}{c}-0.937 \\
\left(-1.43^{*},-0.320\right)\end{array}$ & 0.0055 \\
\hline Other & Deaths & Bombs & 10 & $\begin{array}{c}0.373 \\
(0.329,0.425)\end{array}$ & 0 & 0.47 \\
\hline Israel & Deaths & Bombs & 10 & $\begin{array}{c}0.232 \\
(0.170,0.328)\end{array}$ & 0 & 0.16 \\
\hline Other & Deaths & Guns & 20 & $\begin{array}{c}0.340 \\
(0.236,0.518)\end{array}$ & 0 & 0.62 \\
\hline Israel & Deaths & Guns & 5 & $\begin{array}{c}0.155 \\
(0.071,0.390)\end{array}$ & 0 & 0.034 \\
\hline
\end{tabular}

${ }^{a}$ Model fits were performed conditional on the specified value of the threshold parameter $u$ of the generalized Pareto model (or corresponding trend model, indicated by parameters $\square$ and $\square$ ), and if $\mathrm{p}_{\square \neq 0}>$ 0.01 also on $\square=0$ (see Methods). Other $=$ all other worldwide regions besides Israel. A $\mathrm{p}_{\square \neq 0}$ value $<10^{-15}$ is indicated by $\sim 0$. Confidence limit (CL) values listed were obtained by the profile likelihood method, or if that method failed to converge, by the delta method (indicated by *).

${ }^{b}$ Events included were those during 1968-2004 that resulted in $\geq 1$ case of the specified endpoint. Bombs here includes remote-controlled bombs. 


\section{Figure Legends}

Figure 1. Consequences of terrorist events during 5-y periods starting in 1968. (A) Adverse terrorist events (AE); pre-1998 events are "international" (I) only, post-1997 events also include “domestic" events (I\&D). I-only data show a positive trend (solid line, $\mathrm{R}^{2}=0.71, \mathrm{p}=0.035$ ). The linear fit (dashed line) estimated from post-1997 data is conditional on the intercept $\left(\mathrm{X}_{\mathrm{o}}\right.$ $\square 1956)$ estimated from pre-1998 data. The I\&D slope is $\sim 4.8$ times greater than the I-only slope.

(B) Adverse fraction $\left(F_{\text {adv }}\right)$ of all events that occurred in: Israel $(\square)$, Region 1 ( $\bullet$ Africa, Latin America, Near East [excluding Israel and the Occupied Territories], and South Asia), and all other regions combined (O). Region 1 data show a positive trend (long-dashed line, $\mathrm{R}^{2}=0.92$, $\left.\mathrm{p}_{\mathrm{adj}}=0.00055\right)$, while data for Israel (mean $=0.60$, upper short-dashed line) and Region2 (mean $=0.27$, lower short-dashed line $)$ do not $\left(\mathrm{p}_{\mathrm{adj}}>0.80\right)$. (C) Linear fits to pre-1998 data on casualties (bold line, $\mathrm{R}^{2}=0.83, \mathrm{p}=0.012$ ) and deaths (thin line, $\mathrm{R}^{2}=0.75, \mathrm{p}=0.027$ ) are shown, together with fits (dashed lines) corresponding to the two post-1997 data points for each endpoint conditional on $\mathrm{X}_{\mathrm{o}} \square 1969$ estimated from pre-1998 casualty data. Dashed-to-solid slope ratios are both $\sim 4$. (D) Linear fits to data on (total victims)/(total events) ratios are shown for worldwide deaths (lower line, $\mathrm{R}^{2}=0.87, \mathrm{p}=0.00079$ ), and for worldwide casualties (upper line, $\mathrm{R}^{2}=0.51, \mathrm{p}=0.046$ ); the per event casualty-to-mortality slope ratio is $\sim 4.2$.

Figure 2. (A) Total victims/AE during 5-y periods starting in 1968. Significant increasing trends are evident for deaths/AE $\left(\mathrm{R}^{2}=0.51, \mathrm{p}=0.046\right)$ and for casualties $/ \mathrm{AE}\left(\mathrm{R}^{2}=0.58, \mathrm{p}=\right.$ 0.028). (B) Casualty-weighted $F_{\text {fat }}=($ total deaths $) /($ total casualties in all AE) values for Israel $($ mean $=0.17$, lower short-dashed line $)$ vs. all other regions combined (mean $=0.33$, upper shortdashed line $)$, the latter mean being significantly $(\sim 2$-fold $)$ greater $(p=0.0015)$. Both groups show a common non-significant linear trend, with intercepts that differ significantly $(\mathrm{p}=0.00095$ 
by ANOCOVA F-test). Unweighted $F_{\text {fat }}$ values increased slightly from 1968-2004 in combined non-Israeli regions (long-dashed line, $\left.\mathrm{R}^{2}=0.69, \mathrm{p}=0.011\right)$, but not in Israel $(\mathrm{p}=0.22)$.

Casualty-weighted $F_{\text {fat }}$ (solid points) by geographic region ("Near East" here excludes Israel and the Occupied Territories), where point diameter is proportional to total casualties over all periods. For all regions except North America, the $w_{j}$-weighted mean \pm 2 -tail $99 \%$ confidence limits for $F_{\text {fat }}$ is 0.27 (long-dashed line) \pm 0.14 (short-dashed lines). The relatively high $F_{\text {fat }}$ value for North America was due primarily to events on Sept. 11, 2001 (for which $F_{\text {fat }}=100 \%$ ).

Figure 3. Period-specific cumulative relative-frequency distributions of the unweighted ratio $F_{\text {fat }}$ of deaths to casualties per adverse event (AE), for all regions combined. Distributions for successive periods are shown with solid curves of increasing thickness. Later distributions increasingly shift downward and to the right relative to the starting 1968-72 distribution.

Figure 4. (Top) Ratio $F_{\text {fat }}$ of total deaths to total casualties to the total number of adverse events (AE) during 1968-2004, plotted vs. corresponding casualties/AE rates, for gun- or bomb-related events that occurred in Israel vs. all other regions combined. ANOCOVA-estimated intercepts for weapon-specific pairs of log-linear trends shown are significantly lower for Israel than for other combined regions, for events that involved either bombs (dashed lines, $\mathrm{p}=0.029$ ) or guns (solid lines, $\mathrm{p}=$ 0.000038). (Bottom) Among events during 1968-2004 that caused $\geq 1$ victim, the percent that involved guns is plotted vs. corresponding victims/event rates, for events that occurred in Israel vs. all other regions combined. Israeli gun-related percents of fatal events are all $\sim 10$ to $20 \%$ lower than those in other regions; a similar difference for adverse events pertains only to those yielding $<\sim 10$ victims/event.

Figure 5. Cumulative relative frequency distributions of victims/event rates for all events causing $\geq 1$ case during 1968-2004, in Israel vs. all other regions combined. The empirical 
distributions shown differ significantly (by asymptotic Kolmogorov 2-sample test) for data on casualties $(\mathrm{p} \square 0)$ and for data on deaths $\left(\mathrm{p}=1.6 \square 10^{-5}\right)$

Figure 6. Equivalent lifetime (70-year) risks of casualty or death from terrorist events in Israel, the Occupied Territories, the Near East (excluding Israel and the Occupied Territories), and all other regions combined. In the latter regional group, log-casualty risks show a significant positive trend $\left(\mathrm{p}_{\text {adj }}=0.010\right)$ in log casualty risks over 1968-97 prior to inclusion of domestic events in RAND-MIPT data; no other temporal trends are evident ( $\left.\mathrm{p}_{\text {adj }}>0.05\right)$.

Figure 7 Lorenz curves for total deaths and total casualties due to terrorist events that caused $\geq 1$ victim during 1968-2004, in Israel vs. all other regions combined. Light horizontal/vertical lines highlight $50 \%$ of total victims (horizontal), and events associated with $90^{\text {th }}$ and $95^{\text {th }}$ percentile victims/event rates (vertical). The light solid and dashed curves at right, for example, show that $\sim 3 \%$ (and $\sim 10 \%$ ) of all adverse events outside (or inside) Israel caused $\sim 50 \%$ of all deaths and of all casualties in those areas.

Figure 8. (Left) Generalized Pareto model fits to data on extreme values of victims per terrorist event leading to $\geq 1$ case during 1968-2004, by endpoint (casualties or deaths) in Israel vs. all other regions. (Right) Corresponding fits to data on bomb- vs. gun-induced casualties per adverse event during 1968-2004 in Israel vs. all other regions.

Figure 9. Generalized Pareto model fits from Figure 8 (left) with abscissa values re-expressed as expected year during $1980-2080$ by which the indicated maximum victims/event rate has occurred, compared to corresponding empirical data during 1980-2004. 

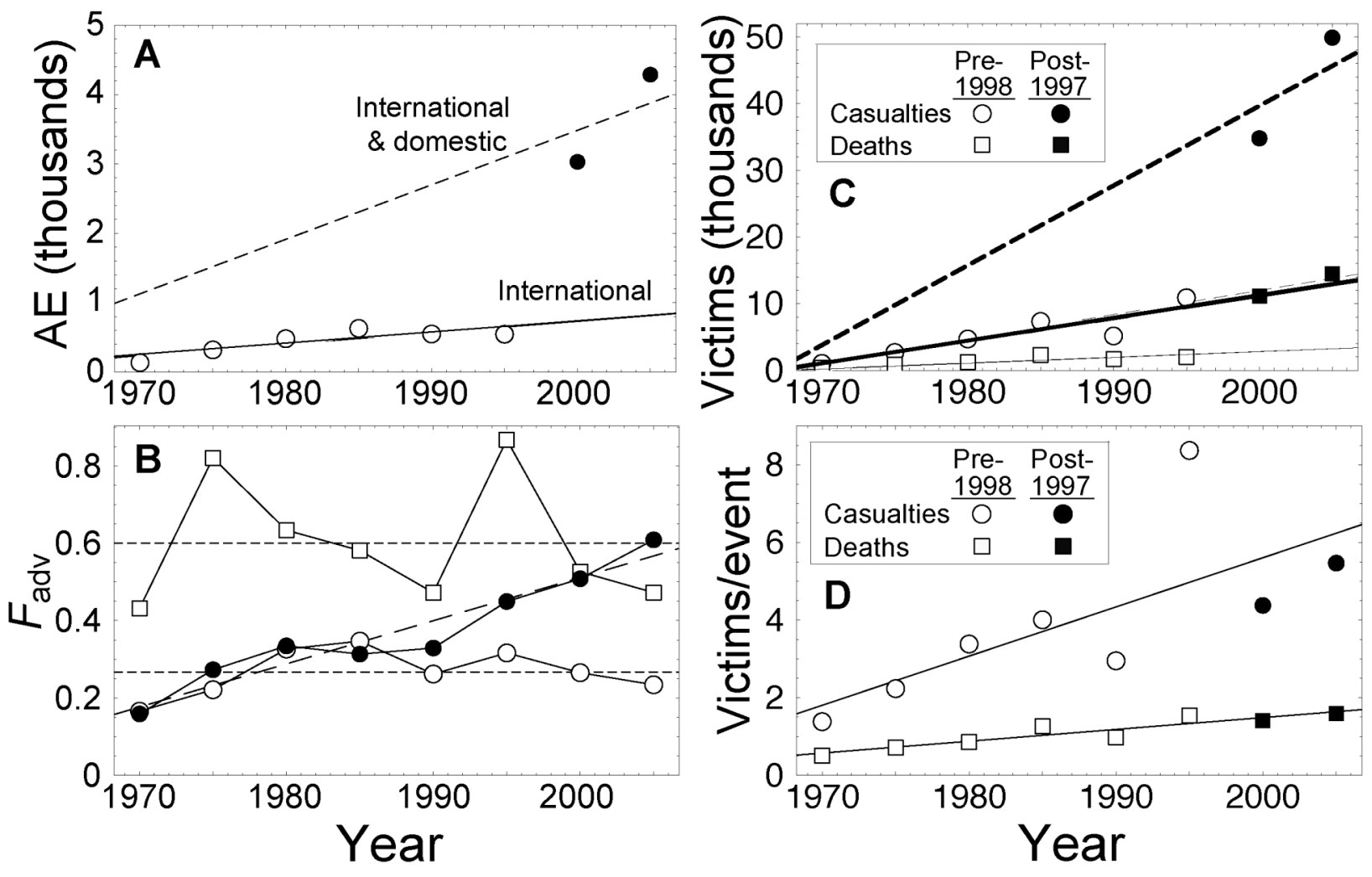

Figure 1 

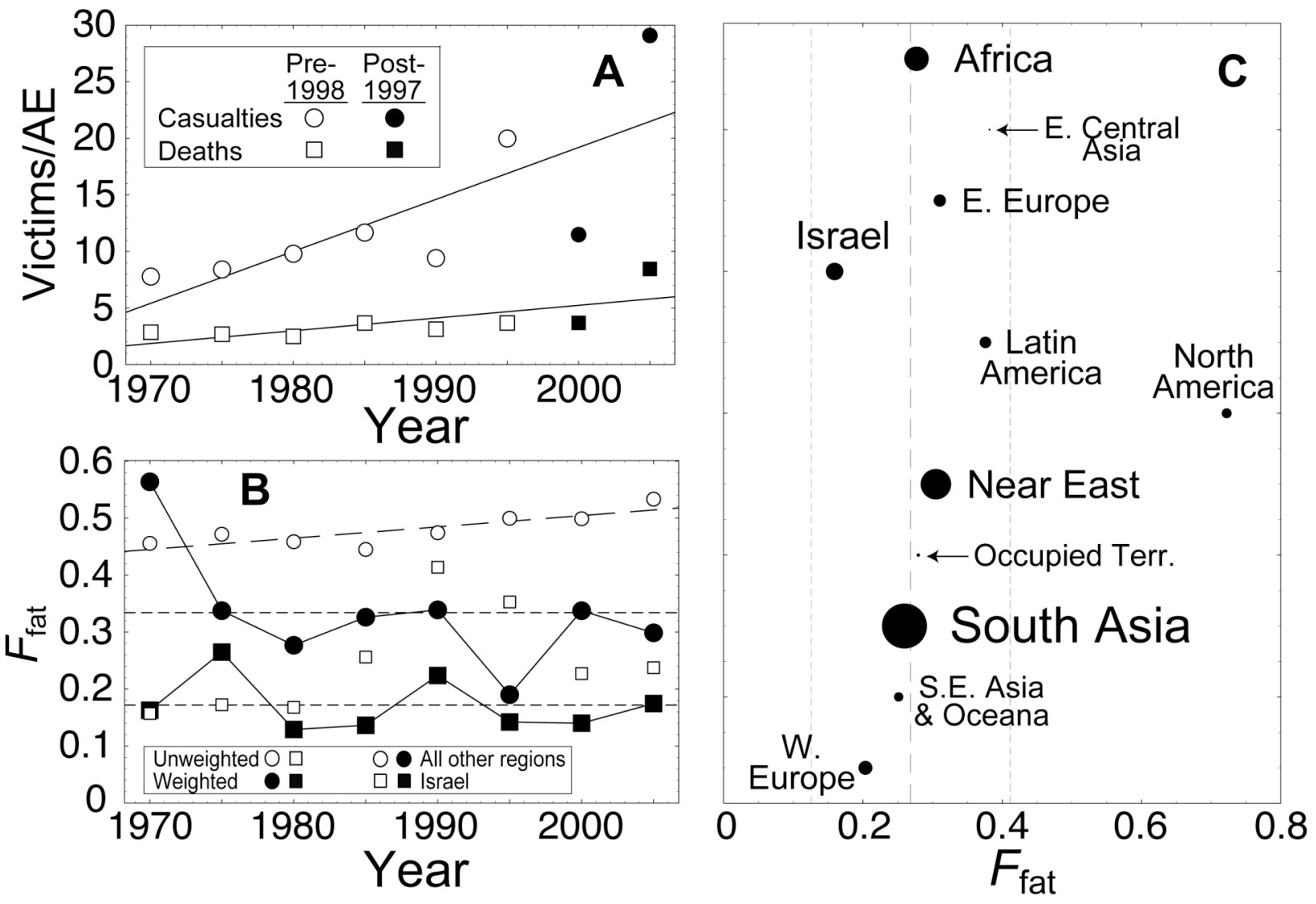

Figure 2 


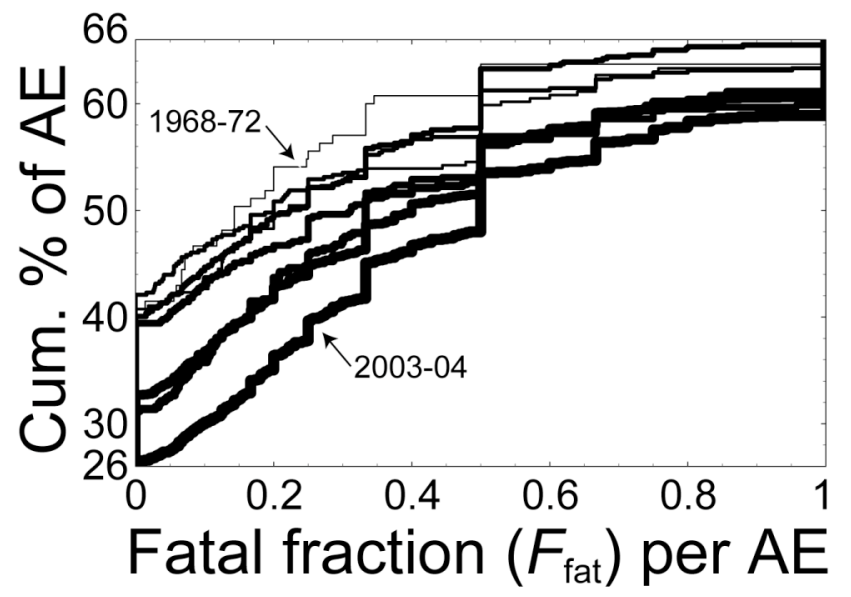

Figure 3 

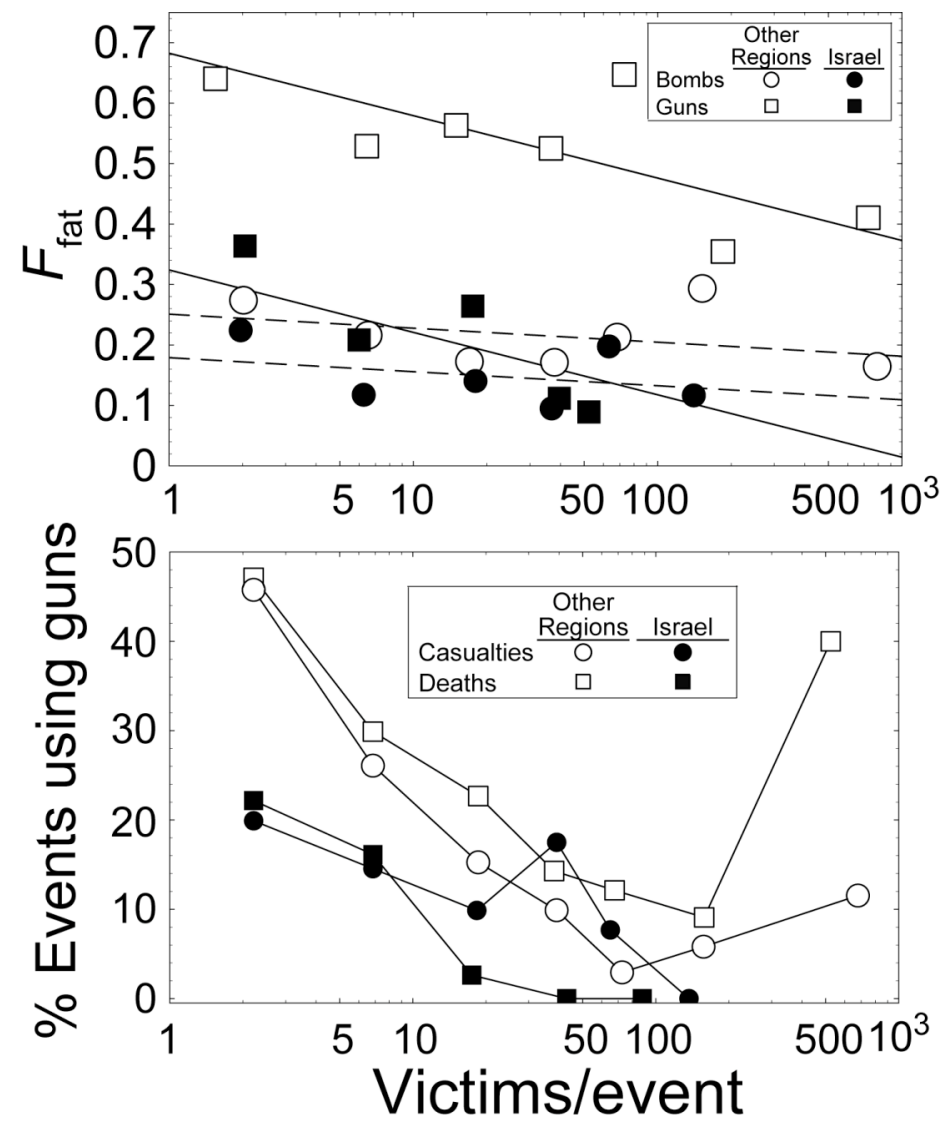

Figure 4 


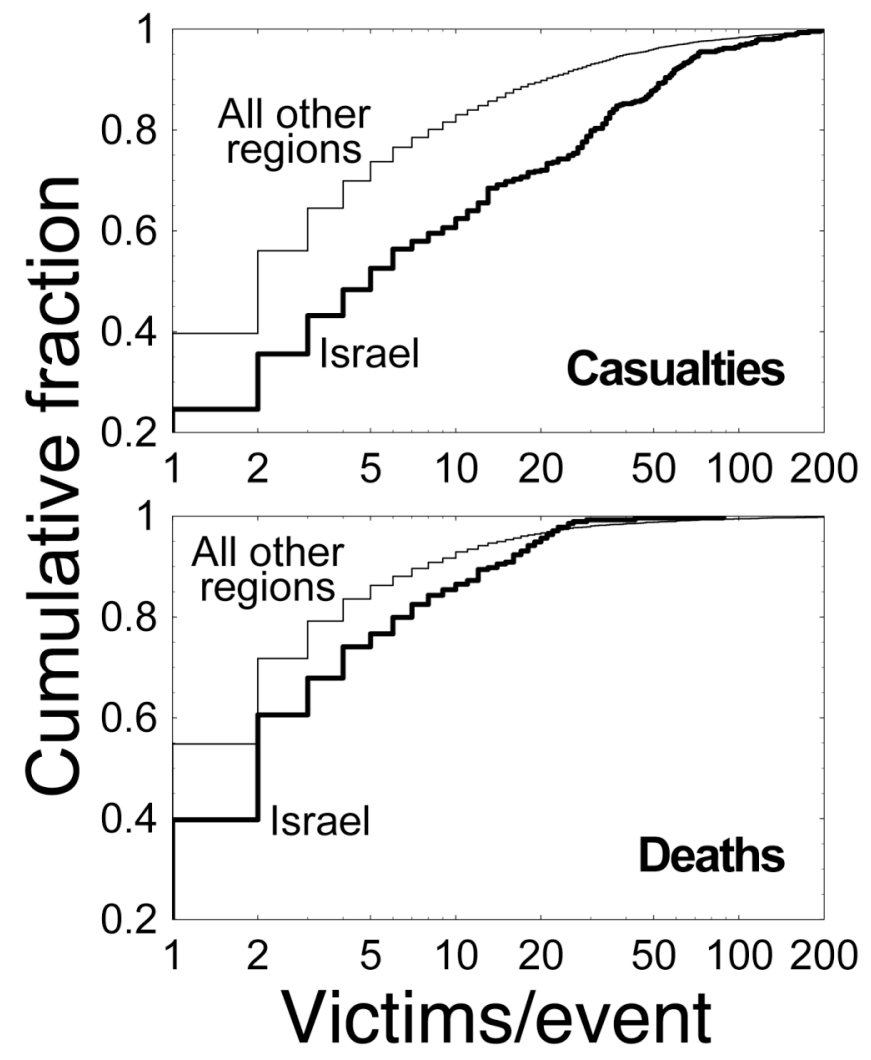

Figure 5 


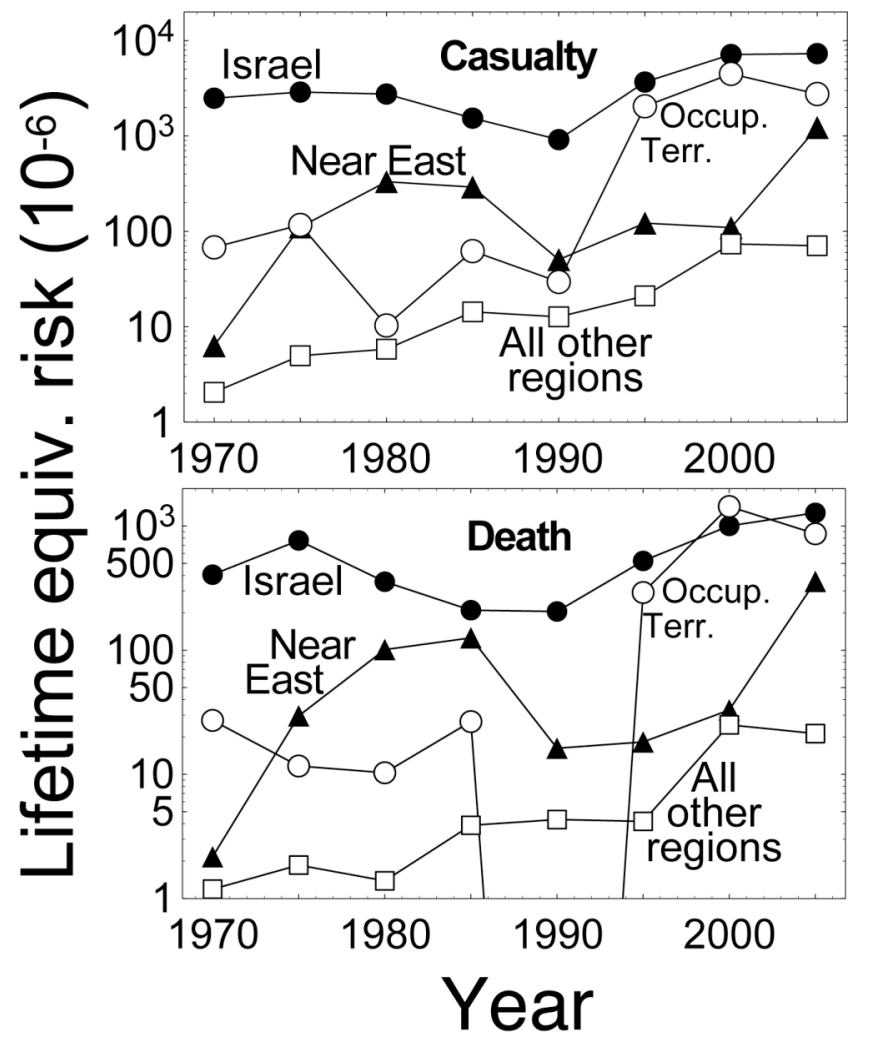

Figure 6 


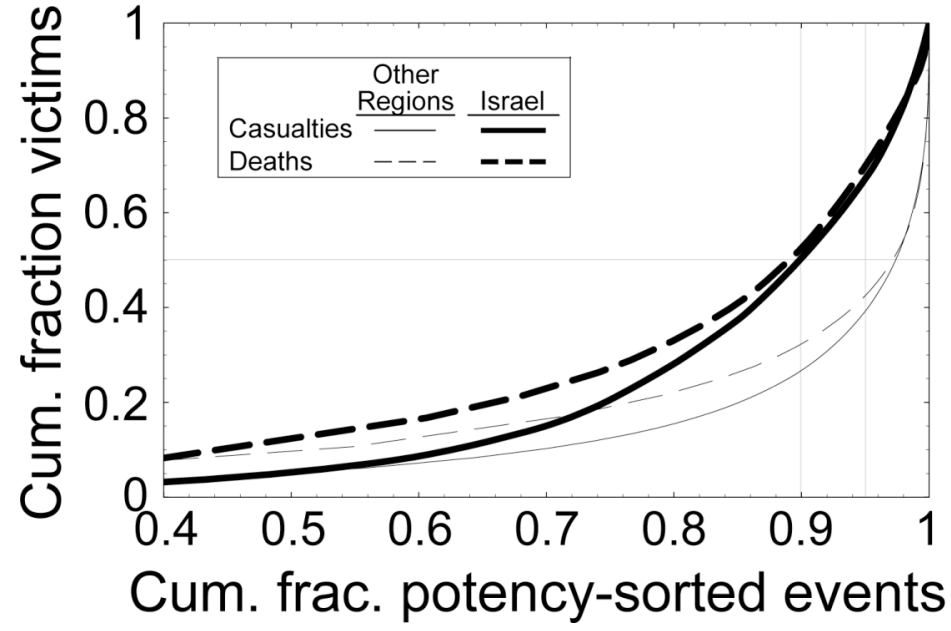

Figure 7 

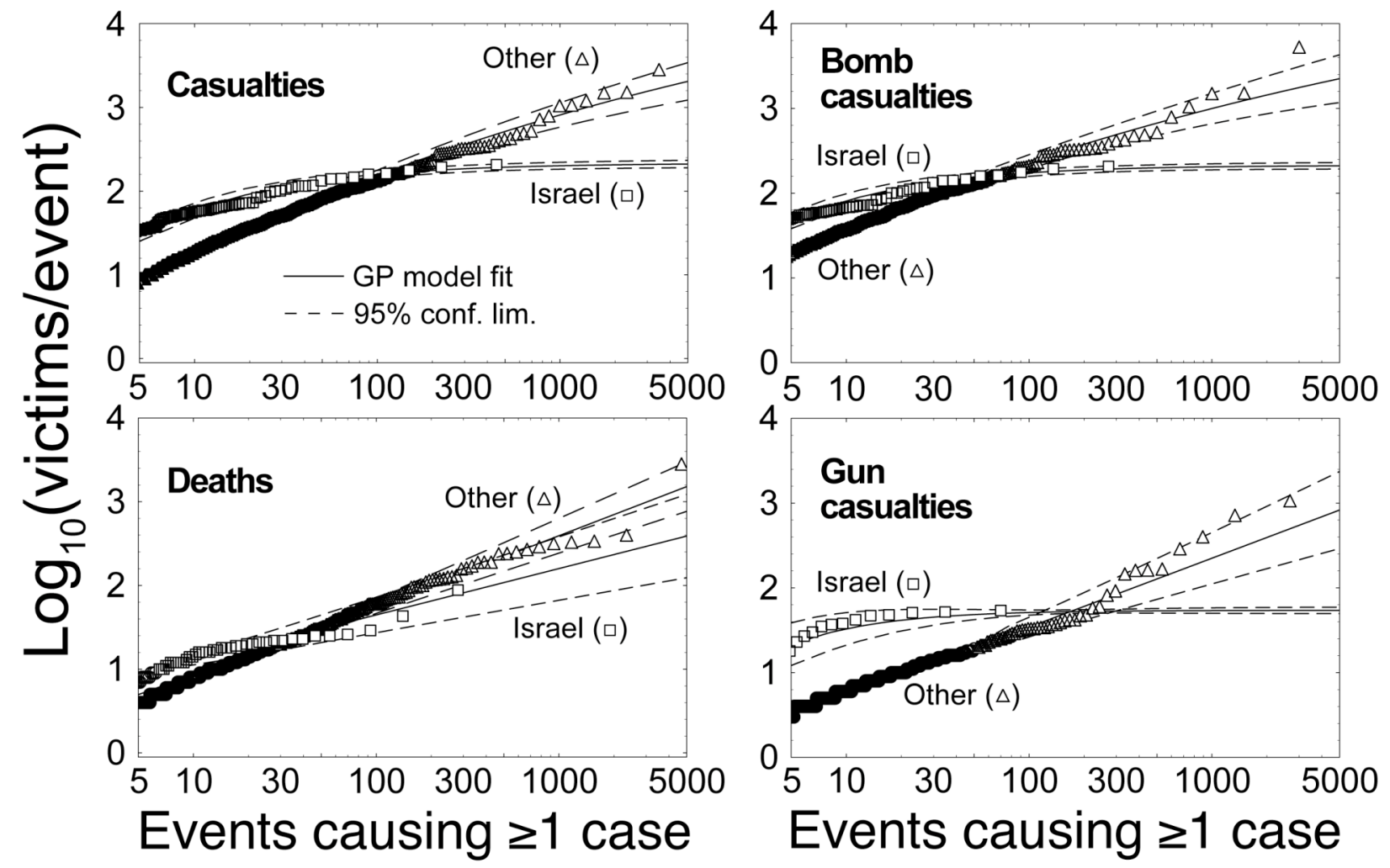

Figure 8 

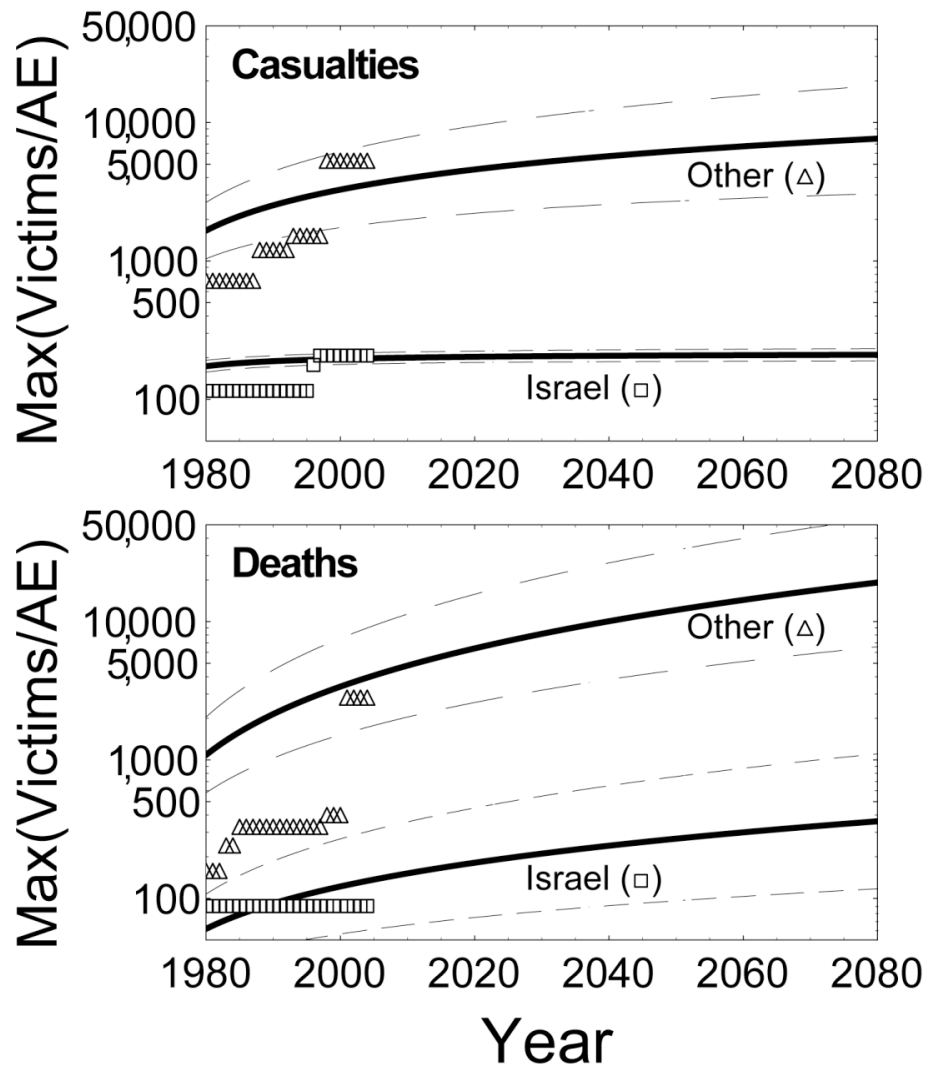

Figure 9 